\title{
A percepção dos moradores do Bairro do Socorro sobre o cemitério e suas implicações com a sustentabilidade
}

O presente estudo tem como foco a discussão sobre a sustentabilidade, com base no Cemitério do Socorro, localizado em Juazeiro do Norte (CE). O objetivo principal desse estudo é relacionar a percepção dos moradores do Bairro do Socorro com a Sustentabilidade e a qualidade de vida. Além de apresentar o conceito de Sustentabilidade e suas dimensões, pesquisar sobre a percepção dos moradores em relação à implicação do cemitério no presente bairro onde moram e relacionar os resultados da pesquisa com a legislação. A metodologia da pesquisa segue uma abordagem quantitativa, com base na pesquisa de campo, instrumentalizada por questionário. A investigação é relevante, pois através dela foi possível compreender a sustentabilidade em dimensões diferentes, além de fomentar uma discussão sobre um assunto que, muitas vezes, só é tratado pelo viés ambiental. No entanto, a sustentabilidade do Cemitério, quando respeitado as normas de implementação e cuidados ambientais, é importante para o crescimento do lugar e dos moradores locais, já que eles juntos somam forças econômicas para o município. Com o estudo, foi possível esclarecer a relação do cemitério com a sustentabilidade, ainda que os moradores desconheçam o verdadeiro conceito de sustentabilidade, que é usar os recursos da natureza buscando não a agredir. Detectou-se ser urgente um programa com ações de conscientização deles, bem como de medidas que fiscalizem e monitorem o solo e água para que contaminações não venham impactar negativamente a vida das pessoas do bairro e da circunvizinhança.

Palavras-chave: Sustentabilidade; Legislação; Cemitério.

\section{Socorro Neighborhood residents' perception of the cemetery and its implications for sustainability}

\begin{abstract}
This study focuses on the discussion on sustainability, based on the Socorro Cemetery, located in Juazeiro do Norte (CE). The main objective of this study is to relate the perception of the residents of Bairro do Socorro with Sustainability and quality of life. In addition to presenting the concept of sustainability and its dimensions, research on the perception of residents in relation to the implication of the cemetery in the present neighborhood where they live and relate the research results with the legislation. The research methodology follows a quantitative approach, based on field research, instrumentalized by questionnaire. The research is relevant, because through it was possible to understand sustainability in different dimensions, besides fostering a discussion on a subject that is often only addressed by the environmental bias. However, the sustainability of the cemetery, when complied with the rules of implementation and environmental care, is important for the growth of the place and local residents, as they together add economic strength to the municipality. With the study, it was possible to clarify the relationship of the cemetery with sustainability, even though the residents do not know the true concept of sustainability, which is to use the resources of nature trying not to harm it. It was found urgent to be a program with awareness actions, as well as measures that monitor and monitor the soil and water so that contamination does not negatively impact the lives of people in the neighborhood and surrounding.
\end{abstract}

Keywords: Sustainability; Legislation; Cemetery.

Topic: Gestão Ambiental e da Biodiversidade

Reviewed anonymously in the process of blind peer.
Received: 11/01/2019

Approved: 14/03/2019
Marileide Dionizio da Silva Nobre

Centro Universitário Dr. Leão Sampaio, Brasil

http://lattes.cnpq.br/9275369954706501

marileide.dionizio@hotmail.com

Ana Isabel Calixto

Centro Universitário Dr. Leão Sampaio, Brasil

http://lattes.cnpq.br/3695894538207689

anaisabel@leaosampaio.edu.br

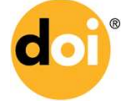

DOI: 10.6008/CBPC2179-684X.2019.001.0009
Referencing this:

NOBRE, M. D. S.; CALIXTO, A. I.. A percepção dos moradores do Bairro do Socorro sobre o cemitério e suas implicações com a sustentabilidade. Revista Brasileira de Administração Científica, v.10, n.1, p.101-116, 2019. DOI: http://doi.org/10.6008/CBPC2179684X.2019.001.0009 


\section{INTRODUÇÃO}

Através da questão ambiental foi que a sustentabilidade começou a ser reconhecida como conceito e prática. Com a elevação da temperatura atmosférica, grandes estudiosos começaram a levantar reflexões sobre as mudanças climáticas e suas implicações em relação a vida no planeta. Começam-se, então, pesquisas no mundo todo. Tem-se o efeito estufa dos gases que são concentrados através da poluição, que atinge a todos indistintamente (DIAS, 2007).

Com a urgência de encontrar alternativas que diminuíssem o aquecimento global, surge, na dimensão ambiental, um novo direcionamento, o econômico. Nos dias atuais, a sustentabilidade tem alcançado muitas pessoas, através de ações que são pensadas a fim de não agredir a natureza, e a implicação dela na sociedade é um diferencial que precisa ser compreendido em diferentes esperas e espaços. Por isso, nesse estudo, focou-se no tema cemitério para discutir a sustentabilidade dentro dessa perspectiva, que ainda é pouco debatida.

O objetivo principal do estudo foi relacionar a percepção dos moradores do bairro Socorro com a Sustentabilidade e a qualidade de vida dos moradores do local. Já os objetivos específicos buscaram: presentar o conceito de Sustentabilidade e suas dimensões; pesquisar sobre a percepção dos moradores em relação a implicação do cemitério onde moram e relacionar os resultados da pesquisa com a legislação.

Deste modo, o problema da pesquisa envolve a seguinte questão: os moradores do Bairro do Socorro conhecem as implicações da sustentabilidade, e a qualidade de vida devido a existência de um cemitério no bairro onde vivem? Nessa conjuntura, elaborou-se a hipótese que os moradores do bairro do Socorro conhecem as implicações da sustentabilidade, mas não apresentam um posicionamento crítico de como o empreendimento pode afetar a sua qualidade de vida.

Considerando o exposto e as razões particulares que levaram a pesquisar esta temática, justifica-se a pesquisa em três perspectivas. A primeira é o interesse do autor pela temática e o desejo de contribuir com discussões sobre o cemitério e suas implicações a sustentabilidade, na perspectiva de sugerir melhorias para a vida dos moradores locais, seja de forma direta ou indireta, mostrando a relevância da sustentabilidade para a região, pois de acordo com Marcondes (2007), os sujeitos precisam interessar-se pela sustentabilidade para cobrar das empresas novas práticas que não agridam o meio ambiente, ou que não prejudique a população. Incitar, discutir sobre o tema é necessário.

Esse tipo de investigação contribui com posicionamentos críticos frente a necessidade de instituir práticas calcadas na sustentabilidade e promove reflexões que podem fazer com que a sociedade passe a se importar mais e buscar juntos as organizações melhores maneiras para utilização do meio ambiente, e que estas não estejam preocupadas apenas com o lucro.

A segunda justificativa tem caráter social, uma vez que é o desejo contribuir de alguma forma, ainda que de maneira tímida, para o desenvolvimento da local. A sociedade precisa compreender a importância da sustentabilidade, mesmo em organizações não convencionais, como é o caso dos cemitérios. Conforme salienta Campos (2007), a sociedade precisa estar a par do desenvolvimento sustentável, compreendendo 
os processos e as dificuldades de promover novas práticas, contribuindo, sempre que possível com o desenvolvimento sustentável, de forma consciente e ativa. Somente a sociedade pode se manifestar em defesa do meio ambiente, pois são os mesmos que o exploram e o agridem, e pensar outras formas de usálo sem contaminar é a principal alternativa.

E por fim, a última justificativa, tem caráter acadêmico e científico, uma vez que ao desenvolver um trabalho dessa natureza, inevitavelmente devolve-se na academia o conhecimento aprendido em forma de trabalho de conclusão de curso, que certamente servirá de referência para outros trabalhos, haja vista, ser esta a finalidade precípua do trabalho. Para a academia é um fator positivo ter alunos pesquisando sobre a sustentabilidade e expondo problemas e sugestões de melhorias para a região, além de promover novos olhares que podem contribuir com outros pesquisadores.

A investigação pode servir para informar como também, abrir novos caminhos investigativos. É para isso que se pesquisa, problematizar e alcançar pessoas interessadas em discutir sobre o assunto, incitando a construção de uma rede de pensadores que podem fazer a diferença no lugar onde se mora, na cidade, no Estado e no país.

\section{REVISÃO TEÓRICA}

\section{Como Nasce a Sustentabilidade}

Desde as primeiras civilizações, o homem precisou se adaptar a mudanças, e algumas dessas interferem na forma como a natureza se transforma. De acordo com Dias (2007), há mais de dez mil anos, após o ser humano se tornar adepto do sedentarismo, mais precisamente desde o período neolítico, passando a se agregar em cidades, vilas e aldeias, todas as práticas desempenhadas por estes impactaram paulatinamente o desenvolvimento do meio ambiente. Após a conhecida Revolução Industrial (séc. XVIII), houve impactos inda maiores por conta da concentração de pessoas no espaço urbano, e isso afeta, sobremaneira, toda a humanidade. Esses impactos refletem atualmente, pois o consumo que se intensificado desde a revolução industrial (CAMPOS, 2007).

Para tanto, quando estudiosos começaram a levantar questões relevantes sobre o meio ambiente e a poluição dele, passou-se a pensar em maneiras de como de diminuir os efeitos desses impactos, vislumbrando os seguintes temas: tecnologia, economia, política, sociedade e ciência. No entanto, a intensão estava pautada, pelo menos, pelos líderes de grandes empresas em resolver problemas ambientais em detrimento dos negócios. No entanto, os questionamentos e discussões alcançaram escalas globais, o que permitiu novas reflexões sobre o futuro da humanidade (MARTINS, 2007).

Desse modo, o efeito estufa, a diminuição da biodiversidade, a redução da camada de ozônio, o aquecimento do planeta, as mudanças no clima, a contaminação do ar e o ecossistema sendo ameaçado, além de água, solo, rios e oceanos, levantou questões polemicas e necessárias, como por exemplo: como diminuir os efeitos dessa crise ecológica causada pelo próprio homem? (DIAS, 2007). 
É claro que o aumento da população também interfere diretamente para os problemas citados acima, pois quanto mais pessoas existirem no planeta, mais matéria prima será extraído da natureza para bens de consumo. Desse modo, entende-se que se a natureza for tratada apenas como matéria de produção, sem a preservação dos recursos naturais, os impactos serão ainda maiores. Com os riscos da degradação do meio ambiente, houve preocupação por meio da comunidade internacional, em meados de 1960, e as discussões levaram a Organização das Nações Unidas a realizar uma conferência do meio ambiente que aconteceu em Estocolmo (1972) (CAMPOS, 2007).

Ainda na década de 1970 surgiu o conceito de ecodesenvolvimento, trazido pelo canadense Maurice Strong, que entendia o desenvolvimento de uma região dentro de seis perspectivas: solidariedade com a geração futura; satisfação das necessidade básicas; preservação dos recursos do meio ambiente; participação da população; programas educativos; efetivação de um sistema que garantisse assistência ao emprego, segurança, e acima de tudo, respeito aos demais povos e culturas (MARTINS, 2004). É necessário, pois, levantar uma crítica social a sociedade industrial, e foram as questões levantadas nesse período que esclareceu a importância de cuidar do meio ambiente, surgindo, assim, o conceito de desenvolvimento sustentável.

Apenas em 1992, a sustentabilidade se consolida como uma ideia que era percebida como força para a questão ambiental. Todavia, ao passar dos anos, os estudos foram se complementando e o números de pesquisadores contemplaram novos problemas causados pelos impactos ambientais, e chamou-se atenção, preferivelmente, para a responsabilidade social, onde o governos e empresas deveriam começar a desenvolver ações que fossem capaz de frear esses impactos e promover soluções para salvar o planeta (DIAS, 2007).

Pontua-se, então, que a sustentabilidade corresponde a uma visão mais ampla sobre o modo como se vive. Ela deve sair de um espaço e adentrar em outro, afetando positivamente a vizinhança e onde se mora, até, de maneira organizada, atingir o mundo todo. Pressupõe-se que a sustentabilidade deve ser instaurada para garantir a qualidade de vida das pessoas.

Com base no exposto, considera-se que, uma organização/empresa, para ser sustentável, necessita ser lucrativa, mas também cuidar corretamente do meio ambiente, sendo responsável com a qualidade de vida da população. Dito isto, as organizações precisam estabelecer uma gestão com ações pautadas na sustentabilidade, e que essas não sejam apenas práticas que pontuem o desenvolvimento da empresa isoladamente. É um processo, e por isso, deve ser discutido, analisado e, se possível, melhorado (MARCONDES, 2007).

Para que uma empresa seja reconhecida como sustentável, a mesma deve ser ecoeficiente, ou seja, oferecer uma produção limpa, favorecer condições de desenvolvimento da cultura consciente sobre o meio ambiente, ter responsabilidade, buscando, constantemente soluções que possam contribuir com as práticas de não contaminação do solo, da água e do ar. Deve-se promover ações que conscientizem os colaboradores e a comunidade sobre a importância de preservar o meio ambiente (DIAS, 2006). 
Na perspectiva de Neira (2007), o conceito de sustentabilidade fica circunscrito como um termo relacionado a ecologia, isto quer dizer que, a responsabilidade sustentável está no uso dos recursos naturais, da tecnologia, com vistas a atender as necessidades do povo, mas de forma limitada, sem afetar a natureza. Já para Mello (2009), a sustentabilidade otimiza as ações das organizações, com vistas a usar corretamente os recursos naturais, mantendo uma uniformidade, mas sem deixar de lado a criatividade que o homem tem. É imprescindível que a sociedade inteira compreenda a sustentabilidade como a principal alternativa de produzir. Os bens retirados da natureza precisam ser bem aproveitados. Não se pode mais consumir por consumir; é preciso uma postura crítica sobre as ações. Dessa maneira, é preciso entender as dimensões que a sustentabilidade apresenta, para poder promover práticas que sejam, de fato, positivas.

\section{Dimensões da sustentabilidade}

Sobre as dimensões que a sustentabilidade pode ter, dentro de uma perspectiva global e não somente organizacional, Sachs (2003) afiança que o desenvolvimento sustentável tem cinco dimensões. A primeira é a econômica, que dentro de um panorama macroeconômico, evidencia-se por meio da gestão eficiente de investimentos, sejam eles públicos ou privados, a fim de promover o crescimento, levando em consideração, as desigualdades sociais, as dívidas dos países, a quebra da proteção entre as nações, e as dificuldades quanto ao uso da tecnologia.

A segunda dimensão é a social, que se caracteriza como uma forma de buscar alternativas sustentáveis para o momento atual, conscientizando sobre como as gerações futuras irão receber o planeta que vivemos hoje. A melhoria da qualidade de vida é a principal base dessa dimensão, o que compreende o acesso a uma saúde melhor, equidade no tocante a distribuição de renda, novas oportunidades sustentáveis de trabalho e melhoria na educação (SACHS, 2003).

Quanto à dimensão ecológica, diz-se que ela corresponde à preservação consciente dos recursos nacionais, onde as pessoas passam a agir racionalmente sobre suas práticas. Entre essas ações, reduzir a quantidade de resíduos, a poluição, criar e aplicar normas de proteção do meio ambiente. Quanto ao processo de produção, é imprescindível que as quantidades dos recursos retirados da natureza sejam pensadas com foco a atender a demanda, não para estocar, evitando a degradação no meio ambiente (DIAS, 2007).

A quarta dimensão vislumbrada é a cultural, que promove mudanças com foco nos valores culturais de cada sociedade. A cultura é para o homem, uma maneira de se reconhecer, e por isso, entender $s$ necessidade de sobrevivência e repassar para as próximas gerações é um fator primordial do processo sustentável. O processo requer mudança de perspectiva e até ideológico, mas é necessário, pois como a natureza precisa adaptar-se a nós, e indispensável, que nos adaptemos para preservá-la (DIAS, 2007).

A quinta dimensão é espacial, e está relacionada ao território, onde se percebe que é necessário um equilíbrio entre as forças da polução e a econômica. É preciso conservar o ecossistema, e preservar aqueles que são mais frágeis. Desse modo, promover técnicas modernas e regenerativas na manipulação e exploração do solo por meio de tecnologias limpas, é no momento, a melhor alternativa (DIAS, 2007). Ainda 
sobre as dimensões da sustentabilidade Elkington (1999 citado por KEINERT, 2007) reconhecido como fundador da Organização Não Governamental SustainAbility, estabelece que

[...] uma empresa só é sustentável se contribuir para o desenvolvimento econômico, mas primeiramente deve levar em consideração o desenvolvimento sustentável para não agredir a natureza e não prejudicar a população. Foi assim que nomeou o tripé da sustentabilidade, apoiando-se em três critérios básicos: equidade social, prudência ecológica e eficiência econômica. O que leva a três dimensões indissociáveis.

Dessa maneira, apresenta-se na figura a seguir as dimensões da sustentabilidade com foco em organizações/empresas. Essas foram elaboradas para fortalecer a relação que existe entre desenvolvimento sustentável e a dimensão econômica, social e ambiental. Propõe-se a figura 1, que traz as dimensões da sustentabilidade organizacional.

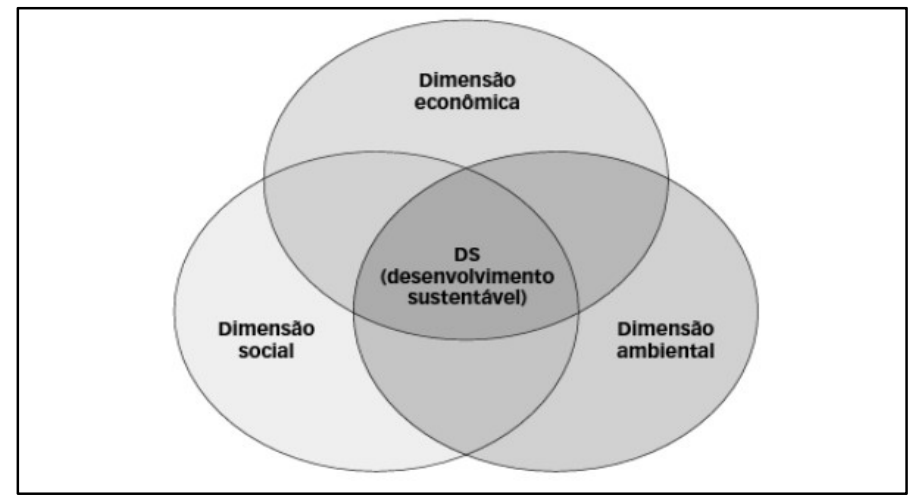

Figura 1: Dimensões da sustentabilidade organizacional. Fonte: Barbieri et al. (2009).

Quando se trata da dimensão econômica, de acordo com Barbieri et al. (2009), as empresas precisam obter lucros, mas devem avaliar as alternativas de investimento e trabalho, sem deixar de lado as outras dimensões: ambiental e social. Precisa-se, pois, considerar "a competência profissional, experiência, habilidade e motivação pessoal, que são o capital humano da empresa, [...] as marcas, patentes e outras formas de conhecimentos explícitos pela legislação da propriedade intelectual” (BARBIERI et al., 2009). É necessário que os gestores das empresas, ao implementares ações de sustentabilidade atentem e considerem os erros, as falhas, os acertos e se comprometa com a responsabilidade social perante toda a sociedade, não apenas com funcionários ou investidores/sócios.

Quanto à dimensão ambiental, pode-se entender que abrange aos recursos naturais que as organizações utilizam, ou seja, "fontes de matérias-primas, sendo em geral classificados como renováveis e não renováveis" (BARBIERI et al., 2009). Conforme explicita Furtado (2005) essa dimensão diz respeito à "conservação e qualidade dos estoques de recursos renováveis, extensão de vida-útil dos não renováveis e sustentação dos serviços naturais, como clima recuperação da fertilidade do solo, garantia da cadeia de nutrientes, entre outros indicadores". É uma dimensão muito citada em reuniões de empresas comprometidas com a conservação do meio ambiente, mas que entra descaso com a primeira dimensão precisa se sobressair, ou seja, quando os lucros são considerados mais relevantes que a sustentabilidade do modo de produzir e usar os recursos naturais.

A terceira dimensão, também citada por Barbieri et al. (2009), é a social, considerada como "a capacidade que surge da prevalência da confiança da sociedade ou em partes dela e um dos seus maiores 
benefícios é a diminuição do atrito social". Essa dimensão está relacionada a todos os processos que são desenvolvidos dentro das organizações, e é importante para a manutenção da sustentabilidade dentro das empresas.

Como se pode perceber vários autores se complementam em relação a definição das dimensões da sustentabilidade, e apesar de muitos deles terem aprimorado o modelo de John Elkington, incluindo outras dimensões, como o caso das primeiras mencionadas nesse estudo, nenhum destes consegue exemplificar ou sugerir soluções para os problemas causados por anos de produção desacerbada e desregular, capitalista. É necessário que pesquisas e estudos sejam feitos para que novos elementos justifiquem outras práticas, já que o conceito, apenas, não resolve tais problemas. Contudo, todas essas dimensões citadas devem funcionar de forma intrínseca para estabelecer um padrão e a partir daí, produzir resultados eficientes.

A organização a qual esse estudo destina-se pesquisar, foge um pouco do padrão de muitas organizações, pois atua com o ramo funerário. Por isso, foi importante conhecer essas dimensões para entender como os cemitérios funcionam e como podem promover a sustentabilidade, mostrando implicações sobre a questão sustentável, o que não é nada comum, já que os cemitérios são empreendimentos reconhecidos por degradar o solo.

\section{Cemitérios}

Falar sobre cemitério não é nada comum, haja vista que não é um tema muito discutido, e por isso a dificuldade de referencial teórico para efetivação de uma pesquisa mais profunda. Quando se busca informações sobre a prática de sepultar cadáveres, inevitavelmente recorre-se à história para entender como esse costume torna-se tão relevante para os dias atuais. Na Idade Média, devido a muitas epidemias e doenças perigosas, os corpos eram enterrados em ambientes abertos, de forma inapropriada, o que permitiu que agentes patogênicos fossem disseminados. Em virtude de prevenção os cemitérios foram implementados, não sendo permitido sepultamento em igrejas ou em terras pertencentes a família (CAMPOS, 2007).

A definição da palavra cemitério origina-se do grego Koumeterian e do latim Coemeteriun, e quer dizer 'espaço onde se dorme', 'onde se encontra a última moradia' (CAMPOS, 2007). Dessa maneira, os cemitérios passaram a ser compreendidos como lugar, construção que abriga os entes queridos, que precisam ser lembrados e de uma certa forma, pelo sepultamento do corpo físico, perpetuar a memória destes. No Brasil, muitos cemitérios foram construídos de forma inadequada, o que pode favorecer ou propiciar impactos ambientais, como: alterações biológicas, físicas e químicas, além de uma possível saponificação ${ }^{1}$ (PACHECO, 2006). Existem alguns tipos de cemitérios, e os mais conhecidos são os verticais, crematórios ou jardins e os tradicionais.

Como se percebe, os cemitérios funcionam a muitos anos como medida para sepultar cadáveres e evitar a manifestação de doenças que podem ser disseminadas se não houver o sepultamento do corpo. Mas,

\footnotetext{
${ }^{1}$ Essa condição acontece quando a umidade do solo fica alta, retardando a decomposição do cadáver. Nos cemitérios do Brasil, por causa do clima úmido e quente, e, do acúmulo de água subterrâneas que invadem as sepulturas esse processo é considerado comum.
} 
mesmo após o sepultamento, qual a garantia de que não haja poluição do solo e contaminação de águas? Como o cemitério pode, dentro do segmento empresarial contribuir com a preservação do meio onde vivemos?. As questões levantadas são importantes para que se pense na sustentabilidade como alternativa e prática. A exemplo disso, tem-se os cemitérios ecológicos, que tem em sua concepção básica a preocupação com a construção das gavetas (lóculos) e com as práticas que envolve limpeza e administração.

Os cemitérios ecológicos oferecem benefícios significativos para o meio ambiente e causam baixo impacto no mesmo, já que o corpo não tem contato com o solo e lençol freático. Entretanto, com base em uma pesquisa da Revista Superinteressante, $80 \%$ da população procura os cemitérios tradicionais, sem se preocupar com o meio ambiente. Em decorrência disso, o meio ambiente acaba sendo poluído com substâncias tóxicas do corpo em decomposição (CHAYAMITI, 2009). Diante do exposto, o cemitério ecológico é uma importante alternativa para contribuir com a preservação do meio ambiente. Sabe-se que o ensejo e cortejo dos mortos é algo muito particular, o que envolve valores culturais, sociais e religiosos, no entanto, é preciso pensar nos impactos que as ações praticadas hoje podem influenciar, sobremaneira, a vida das gerações vindouras.

\section{METODOLOGIA}

Do ponto de vista de sua natureza, a pesquisa é classificada como básica, visto que foi instaurada a fim de trazer respostas sobre a sustentabilidade de cemitérios, mas não apresenta nenhuma aplicação por parte do pesquisador (GIL, 1999). Do ponto de vista aos objetivos, a pesquisa é descritiva, pois descreve as características da população do Bairro Socorro com foco em suas opiniões sobre o cemitério local (GIL, 1999), o que permitiu realizar um levantamento de dados sobre o que esses investigados entendem por sustentabilidade. A abordagem usada no estudo corresponde a do tipo "quantitativa", pois é aquela que permite quantificar os dados, ou seja, tabular o que foi colhido em informação e apresentar de modo sucinto e claro (MINAYO, 2001).

O procedimento técnico foi o levantamento, pois com este foi possível fazer um questionamento direto dos investigados (GIL, 1999). Cabe pontuar, que o momento do levantamento é aquele que mais demanda tempo e esforço na pesquisa, pois o pesquisador deve convencer os participantes da importância de responderem as suas indagações. A área determinada foi o Bairro do Socorro, localizado no município de Juazeiro do Norte (CE). Os participantes são voluntários e moradores do bairro. Todos os investigados se comprometeram com a pesquisa, já que entenderam o significado dela. O instrumento usado para coletar os dados foi o questionário. Isso foi elaborado com 12 questões, todas fechadas, onde o pesquisado teria que responder com um $X$ entre parêntese, em respostas positivas ou negativas a pergunta instaurada.

\section{RESULTADOS E DISCUSSÃO}

Os dados coletados durante a pesquisa foram tabulados e em seguida transformados em gráficos para melhor demonstrar os resultados. De acordo com o IBGE, moram no Bairro do Socorro cerca de 2.421 pessoas. No entanto, a pesquisa atingiu em torno de $5 \%$ da população. Os questionários foram distribuídos 
a homens e mulheres que moram em torno do cemitério no Bairro Socorro. A quantidade foi estipulada para se ter um número exato de participantes que pudesse, além de ser expressivo, ajudar na tabulação dos dados. Todos foram entregues respondidos. A primeira pergunta do questionário foi sobre sexo, idade e escolaridade, no gráfico a seguir pode-se acessar as respostas:

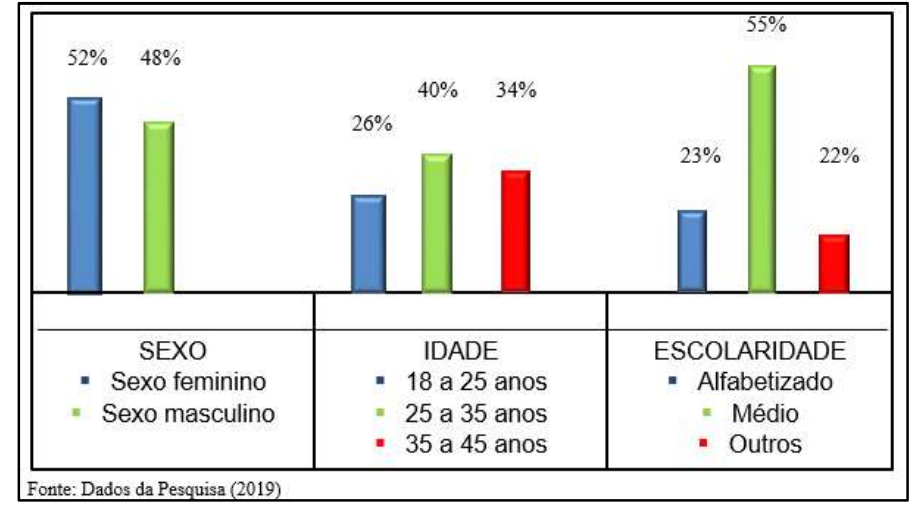

Gráfico 1: Sexo, idade e escolaridade dos moradores (investigados).

Como se pode ver, o sexo masculino corresponde a $52 \%$ dos participantes, enquanto o feminino equivale ao número de 48\%. Já em relação à idade, aqueles entre 18 e 25 anos somam 26\%, os que tem entre 25 e 35 anos foram 40\%, e os que possuem entre 35, 45 anos ou mais somam 34\%. Quando ao nível de escolaridade, $23 \%$ responderam que são alfabetizados, enquanto 55\% revelam que concluíram o ensino médio, no entanto, $22 \%$ marcam a opção outros como resposta. Ou seja, nessas respostas que somam $22 \%$ pode ter analfabetos como, também, pessoas que atingiram o curso superior.

Após as respostas pessoais citadas acima, procurou-se saber da opinião dos pesquisados sobre o cemitério, mais precisamente sobre a questão ambiental que envolve a permanência deste no local. Desse modo, foi perguntado se os moradores acreditavam que a presença de um cemitério no centro da cidade, que é onde fica localizado o bairro do Socorro, pode contaminar a água e o solo, e as respostas ficaram divididas.

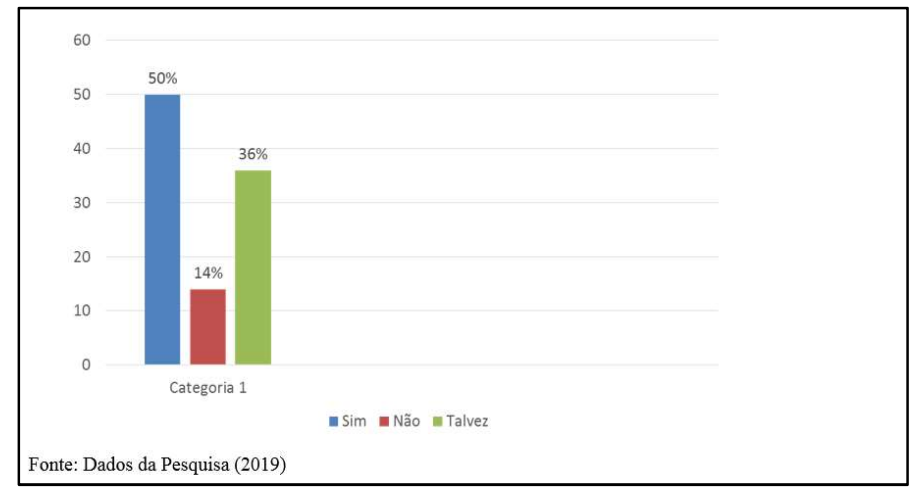

Gráfico 2: Você acha que um cemitério no centro da cidade pode contaminar água e solo?.

Sobre a contaminação $50 \%$ dos moradores consideram que o cemitério pode contaminar o solo e a água, $14 \%$ revela que não, e 36\% fica em dúvida, respondendo à questão posta como talvez, ou seja, não tem certeza se a presença no cemitério pode prejudicar a água e o solo do bairro, e consequentemente da região. Compreende-se que o solo nada mais é do que uma camada formada por partículas orgânicas e minerais, que são distribuídas de forma variável. 
A degradação do corpo no solo, pode trazer malefícios para a saúde das pessoas, bem como quando a água (EMBRAPA, 2006). É preocupante quando as águas subterrâneas, em um processo natural preenche os espaços vazios, até mesmo a água da chuva que transporta compostos químicos para o solo. Por isso é imprescindível que se faça um monitoramento sobre a qualidade da água na área onde possui cemitério (KEMERICH et al., 2013).

Quando o cemitério é localizado em áreas urbanas, como é o caso do cemitério do Bairro do Socorro, é preciso que se tenha uma investigação a fim de monitorá-lo, visto que se o local for impróprio, pode causar contaminação hídrica, permitindo a proliferação de microrganismos em decorrência da decomposição dos corpos. Se houver contaminação, os riscos são enormes, tanto para quem mora na localidade quanto para as regiões circunvizinhas, pois as doenças de veiculação hídrica podem afetar as pessoas através da água. Pensando nisso, a terceira questão intentou conhecer a opinião dos moradores sobre a estrutura do cemitério, para entender se ele tem condições de permanecer no centro da cidade e sobre isto, responderam conforme está proposto no gráfico 3.

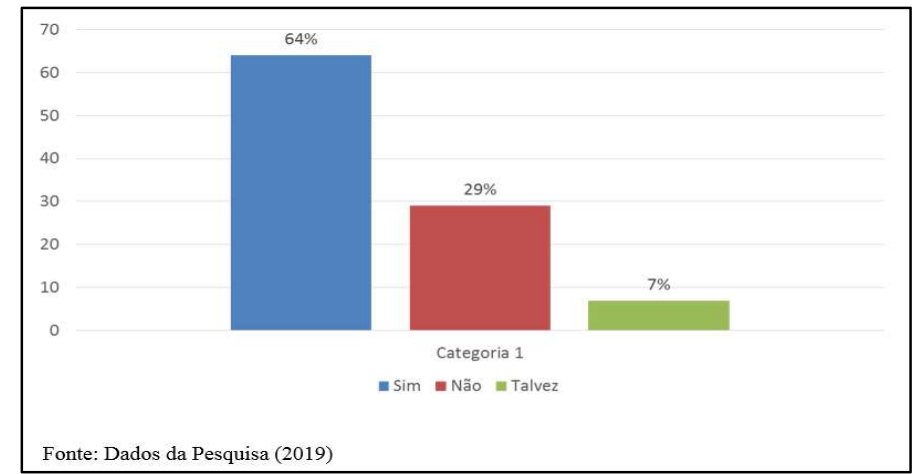

Gráfico 3: Você acha que o cemitério do Socorro tem estrutura para permanecer no Centro?.

A pergunta sobre estrutura do cemitério fez $64 \%$ responderem que o cemitério teme estrutura para permanecer no local. Acredita-se que esse número de pessoas percebe o cemitério como um monumento que já faz parte da cidade, do cenário, da cultura local, já se acostumaram. Já $29 \%$ revelam que o cemitério não tem estrutura para permanecer no Centro da cidade, enquanto apenas $7 \%$ concordam que talvez 0 cemitério tenha estrutura adequada.

Para compreender melhor a questão sobre estrutura, entende-se que os cemitérios que foram construídos dentro da Resolução nำ335 devem seguir as regras estabelecidas, ou seja, os cemitérios precisam usar materiais com coeficientes de permeabilidade (entre $10-5$ e $10-7 \mathrm{~cm} / \mathrm{s}$ ) com base no nível do lençol freático e o fundo das sepulturas, sendo que os jazigos devem ser dez metros acima do lençol freático (CONAMA, 2003). Desde o ano de 2003 as instalações têm sofrido mudanças, não podendo ocupar lugares que o lençol freático passe por baixo, ainda instituíram normas sobre os jazigos para evitar contaminação do necrochorume (CONAMA, 2003). Em detrimento da proposta do estudo, foi perguntado, ainda, sobre o saneamento ambiental, se o bairro tinha esse serviço. E sobre essa indagação os pesquisados salientaram: 


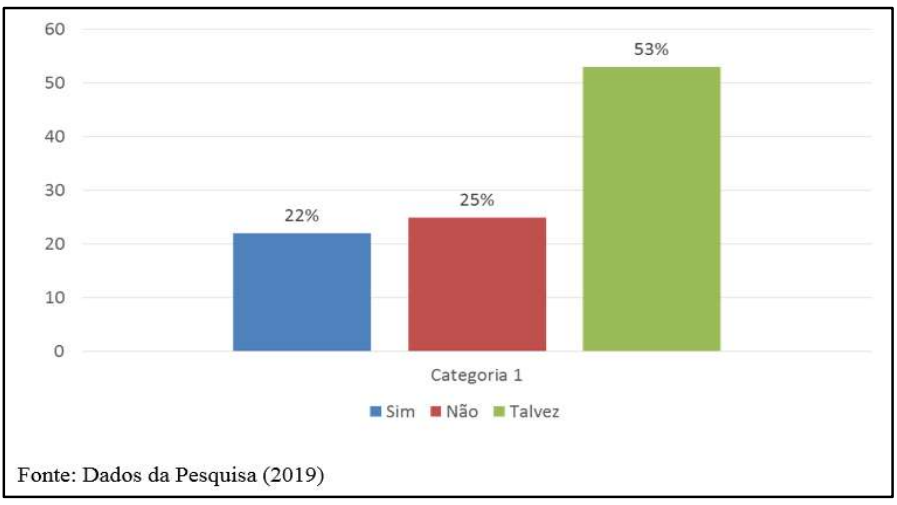

Gráfico 4: Tem saneamento básico no seu bairro?

Diante do exposto, apenas $22 \%$ disseram ter saneamento no bairro, enquanto $25 \%$ revelou que não. O que se acentua como preocupante, nessa altura, é que $53 \%$ responda que talvez o bairro tenha saneamento básico. Sabe-se que um bairro sem saneamento pode trazer danos a comunidade, e esses podem vir em forma de doenças e prejuízos à saúde.

O saneamento ambiental é um serviço indispensável para áreas urbanas, pois através dele prevê-se impactos gerados por implementações inadequadas. O saneamento é parte da infraestrutura urbana e precisa ser estabelecida de forma a melhorar a qualidade de vida da população, e esta deve estar ciente da relevância desse serviço, visto que, ele inclui tratamento de água e esgoto, coleta de lixo etc. (CONAMA, 2003). Na pergunta seguinte, intentou-se saber se já havia sido feita alguma análise de água no bairro por causa da presença do cemitério no local, o que se considerou muito importante saber.

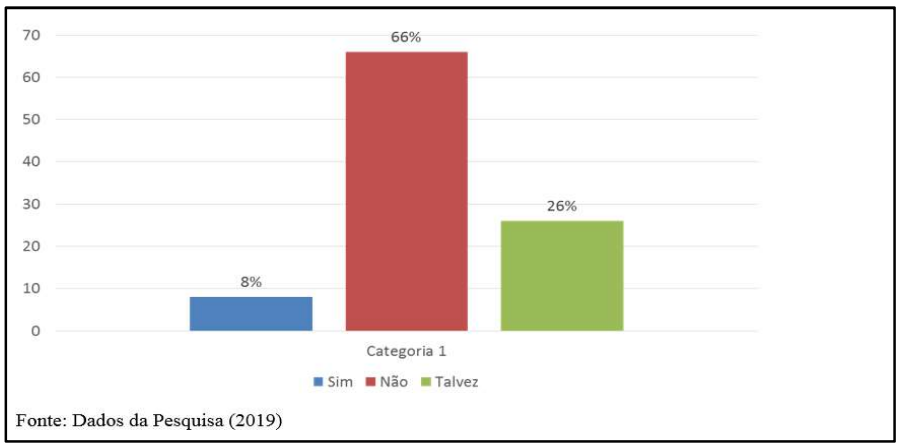

Gráfico 5: Já foi feita alguma análise na água do seu bairro por conta da presença do cemitério?.

Entre os pesquisados, $8 \%$ disseram saber sobre alguma análise feita na água do bairro, enquanto $66 \%$ afirmam que não foi feita nenhuma análise, enquanto $26 \%$ responderam talvez ter sido feita uma análise, mas não sabem ao certo. Fazer o monitoramento da água do bairro onde localiza-se um cemitério, não só é relevante, como necessário, pois é através das análises da água que se pode perceber se existe alguma contaminação e que nível essa pode estar para serem tomadas as medidas cabíveis (CONAMA, 2003). Foi perguntado ainda, se já teve algum caso de infecção por meio da água que consomem. Sobre a infeç̧ão através da água, $13 \%$ dos moradores disseram que já foi comprovada a infecção por meio do uso da água do bairro, no entanto, $66 \%$ salientaram nunca ter percebido nenhuma infecção, e $21 \%$ responderam que talvez. 


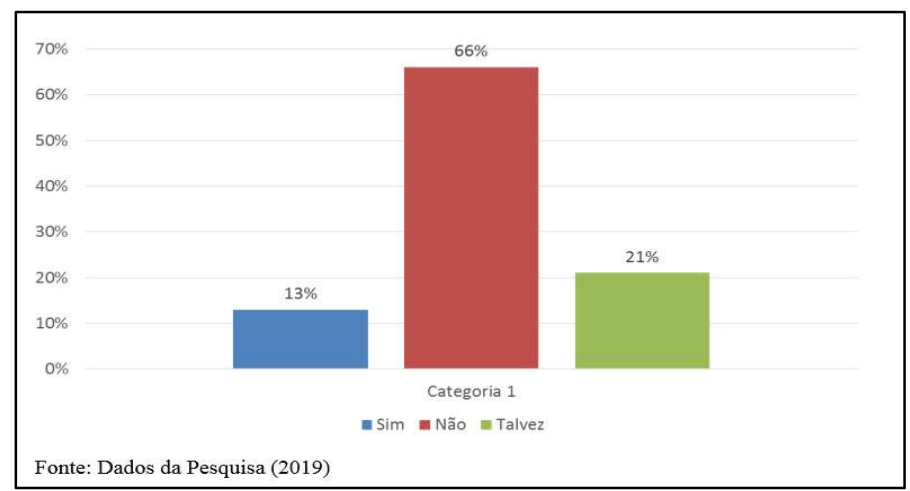

Gráfico 6: Já teve algum caso de infecção através da água?.

A contaminação em cemitérios pode ser ocasionada nas águas subterrâneas ou superficiais por causa de microrganismos patogênicos e destruidores de matéria orgânica, vírus e substâncias químicas liberadas, além da existência de artrópodes e bactérias. Dessa maneira torna-se indispensável o monitoramento da água em locais que tenham cemitérios (MEGLIORINI, 2004). Em continuidade às questões do questionário, foi perguntado se os moradores apoiariam o afastamento do cemitério para outra área mais reservada do bairro, e eles responderam o que está proposto no gráfico 7.

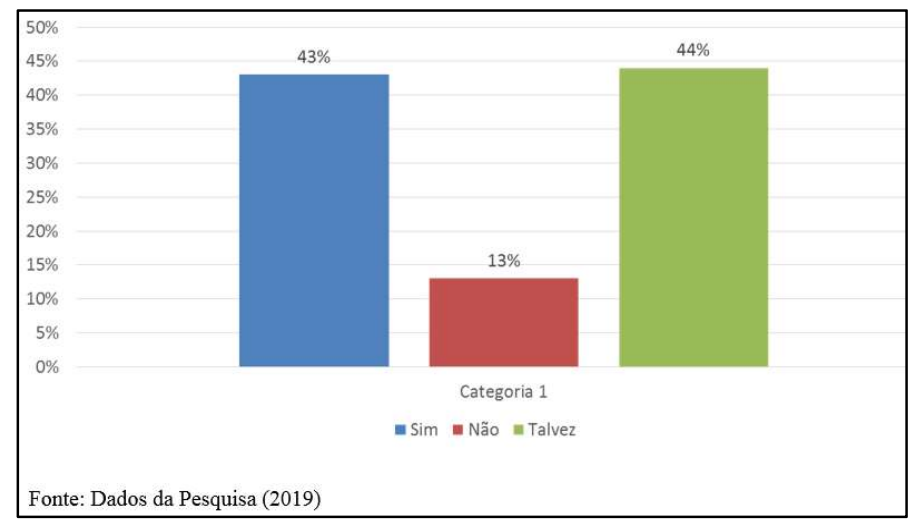

Gráfico 7: Você apoiaria o afastamento do cemitério para uma área mais reservada do centro?.

Como percebido, $43 \%$ dos investigados apoiam o afastamento do cemitério para uma área mais reservada do centro da cidade, enquanto $13 \%$ não apoiam, e $44 \%$ revelam que talvez apoiem. Os motivos pelos quais os moradores apoiam ou não o afastamento do cemitério não ficaram explícitos, embora compreenda-se que o cemitério é uma importante fonte de renda para o local.

Apesar de a maioria dos investigados apoiar o afastamento do cemitério, é imprescindível lembrar que o mesmo, é sinônimo, dentro de uma perspectiva histórica, um monumento que traduz a força da religiosidade do povo, onde o trabalho está diretamente relacionado a fé do povo e se complementam pelos fatores sociais, econômicos, e entre o espaço que foi construído e o que é vivido (ARAÚJO, 2005). Diante do exposto, buscou-se, ainda, compreender sobre os problemas de saneamento no bairro. Dos participantes da pesquisa, $48 \%$ disseram que os problemas de saneamento são frequentes no bairro, já $43 \%$ reconhecem que não. Enquanto apenas $9 \%$ responderam talvez. 


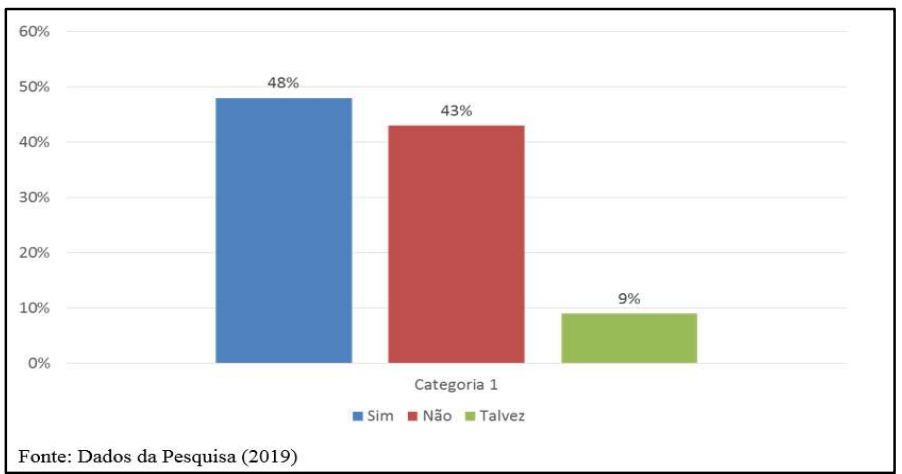

Gráfico 8: Os problemas de saneamento são frequentes no seu bairro?.

Entende-se que os cemitérios podem ser um potencial risco para o meio ambiente. Isso acontece por inúmeras questões, o risco de contaminar o solo e a água, causar impactos ambientais que podem ser irrecuperáveis, favorecer a proliferação de doenças etc. (PACHECO, 2006). É necessário que a população que mora no entorno do cemitério receba um saneamento básico efetivo.

Desse ponto de vista, a gestão do cemitério e a prefeitura precisam estabelecer critérios de cuidados e manutenção do espaço, para que não se tenha danos na qualidade e na saúde dos moradores do Bairro do Socorro. Intentou-se, também, saber que benefícios o cemitério traz aos moradores do bairro, e eles afiançaram o que está descrito no gráfico 9.

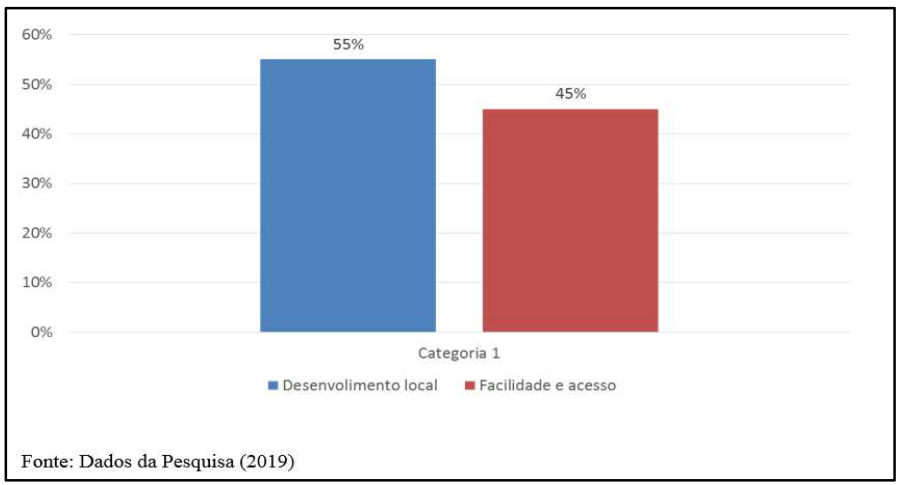

Gráfico 9: Que benefícios o cemitério traz para os moradores do bairro?.

Em relação aos benefícios que o cemitério traz, foi dada duas opções básicas de repostas, e 55\% afirmaram que esses benefícios correspondem ao desenvolvimento local e $45 \%$ revelam que eles estão relacionados a facilidade e acesso dos moradores ao cemitério. Para eles, ter um cemitério mais perto de casa, auxilia com os ensejos e sepultamento dos seus entes queridos.

A cidade de Juazeiro do Norte volta-se ao turismo religioso de uma forma constante, e os moradores revelam que o cemitério é parte da memória que esses indivíduos têm do lugar, bem como eles mesmos. 0 acesso ao local, para muitos, é sinônimo de comodidade. O que se detecta é que os sujeitos precisam manifestar de forma crítica suas opiniões, e para isso, é preciso que tenham consciência sobre os impactos do cemitério no local, demonstrando a importância da sustentabilidade como forma de diminuir, progressivamente, os dados causados no meio ambiente, o que pode afetar a qualidade de vida dos mesmos.

É pretérito que agentes sociais e gestão da organização falem a mesma língua, que todos estejam envolvidos em ações que tornem a vida dos moradores mais segura, e que conserve a natureza de forma 
sustentável, sem agredi-la. Para tanto, última pergunta do questionário voltou-se a responder uma questão crucial do trabalho, que se relaciona diretamente ao objeto de estudo, mas que fecha com coerência a proposta dele. Buscou saber se os moradores acreditam que o cemitério seja um empreendimento sustentável.

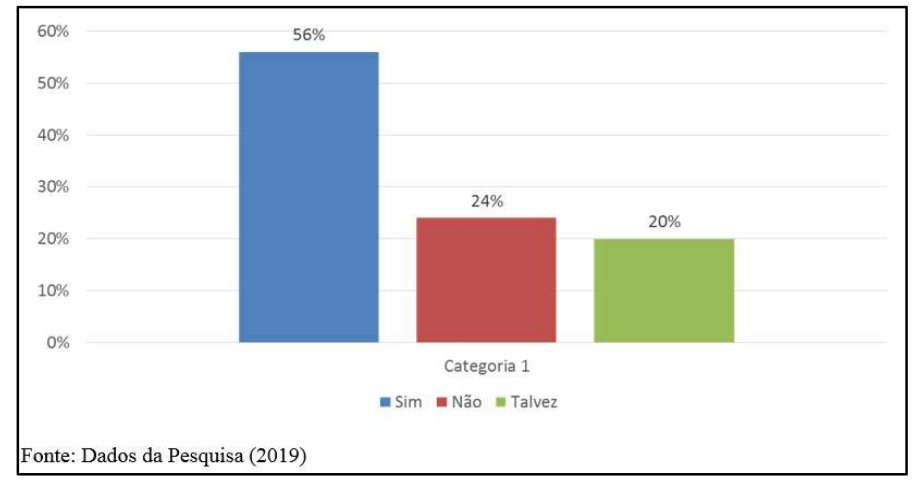

Gráfico 10: Você acredita que o cemitério seja um empreendimento sustentável?.

Ao manifestarem suas opiniões sobre a sustentabilidade do cemitério, $56 \%$ dos moradores revelam que ele seja um empreendimento sustentável, enquanto $24 \%$ responderam que não, e $20 \%$ considera que talvez. Para que um cemitério seja sustentável ele precisa obedecer a critérios legislativos e assumir o compromisso com o meio ambiente e as pessoas.

Como a maioria dos pesquisados, responderam que o Cemitério do Socorro é um empreendimento sustentável, buscou-se no referencial teórico, respostas para contextualizar as respostas, entretanto, as pessoas costumam criar seus conceitos de sustentabilidade partindo da premissa: "se algo não me faz mal, pode ser considerado algo que faz bem ao meio ambiente e a mim" (DIAS, 2007). Pelos critérios que foi abordado no início do estudo, o cemitério do Socorro não é uma organização sustentável, mas os gestores devem mudar sua forma de pensar, pois pode impactar a vida de muitas pessoas negativamente sem os cuidados necessários. É preocupante que a maioria das pessoas não compreenda o que seria um cemitério sustentável, embora tenham noções básicas do entendimento sobre o conceito da palavra.

\section{CONSIDERAÇÕES FINAIS}

A análise dos dados começou pela tabulação deles, onde foram explanados em gráficos e posteriormente discutidos. A pesquisa intentou promover uma reflexão sobre as implicações do cemitério sobre a sustentabilidade. O estudo contou com a participação de cem moradores do Bairro do Socorro, que prontamente responderam ao questionário de pesquisa.

A primeira descoberta, é que os moradores do Bairro do Socorro, em sua maioria, são pessoas jovens, o que nos leva à compreensão de que não acompanharam o momento de construção do cemitério, visto que o mesmo tem quase cem anos de existência; então, quando vieram ao mundo, o cemitério já existia. Desse modo, fica perceptível que, muitos fatores que ocorreram no passado em relação aos impactos do cemitério no local, podem não ter sidos percebidos na investigação, e não ser do conhecimento dos moradores locais.

Sobre a contaminação do solo e água, saneamento básico e estrutura do local para suportar o cemitério, os investigados dividiram-se nas respostas. Percebe-se que o entendimento sobre os prejuízos 
causados se diverge. Alguns acreditam que o cemitério já tenha causado contaminação e se preocupam com esse risco atualmente, outros não sabem responder as perguntas, talvez por não terem sido instigados a pensar sobre isso. Constata-se que, nesse sentido, a investigação foi crucial, pois levantou questões relevantes para a população local.

O saneamento de Juazeiro está longe de ser adequado. Mas é preciso que haja um monitoramento do local de forma constante, pois a contaminação do solo e da água podem trazer prejuízos incalculáveis a vida da população e ao meio ambiente. Ficou claro, também, que ter um cemitério na área urbana incomoda uma parcela considerável de moradores, mas esses nunca se manifestaram oficialmente contra, pois o cemitério faz parte de uma cultura religiosa e tradicional, que de certa forma, é parte da paisagem local. Tem a questão da comodidade, termo escolhido por parte dos moradores para justificar sua opinião sobre a permanência do cemitério no bairro.

Quanto a um possível afastamento do cemitério para outra área reservada, longe do centro da cidade, os moradores, em maioria apoiam a sugestão, no entanto, não tem consciência de como aconteceria essa mudança. Pois de certa forma, afirmam que o cemitério traz benefícios ao local, também, por ser uma organização que promove o turismo religioso, fazendo parte da história local. Já em relação à implicação do cemitério com a sustentabilidade, ficou claro que os moradores desconhecem o verdadeiro conceito de sustentabilidade, que é usar os recursos da natureza buscando não a agredir. Foi percebido que é urgente um programa com ações de conscientização dos moradores, bem como de medidas que fiscalizem e monitorem o solo e água para que contaminações não venham impactar negativamente a vida das pessoas do bairro e da circunvizinhança.

Considera-se, pois, que os objetivos do trabalho foram cumpridos. Mas essa foi uma pesquisa que carece de novos olhares sobre a sustentabilidade, até mesmo para apontar soluções. Pretende-se, portanto, promover, em outro momento, uma investigação mais profunda das relações que se tecem no Bairro do Socorro, e que de alguma forma estejam ligadas ao cemitério e a sustentabilidade.

O questionário foi muito relevante para obter as respostas sobre o que se precisava descobrir. Nessa conjuntura, os moradores do bairro do Socorro conhecem superficialmente as implicações da sustentabilidade, mas não apresentam um posicionamento crítico de como o empreendimento pode afetar a sua qualidade de vida.

É necessário e urgente debates, discussões e reflexões sobre como conscientizar a população em relação a sustentabilidade. As pessoas precisam, também promover ações que dê continuidade a práticas sustentáveis, elas devem exigir isso das empresas, pois é futuro do planeta que está em jogo. A sustentabilidade, é a melhor alternativa para diminuir, progressivamente, os impactos ambientais. Dessa forma, esse estudo serve para consulta e pesquisas na área administração, até porque trata de um tema polêmico e atual, e merece destaque. Cabe pontuar, que a investigação não terá um fim em si mesma, pretende-se dar continuidade a pesquisas que nos leve a uma concepção mais ampla sobre o tema. 


\section{REFERÊNCIAS}

ARAÚJO, M. L.. A Cidade do Padre Cícero: trabalho e fé. Rio de Janeiro: UFRJ, 2005.

BARBIERI, J. C.; CAJAZEIRA, J. E. R.. Responsabilidade social empresarial e empresa sustentável: da teoria à prática. São Paulo: Saraiva, 2009.

CAMPOS, A. P. S.. Avaliação do potencial de poluição no solo e nas águas subterrâneas decorrente da atividade cemiterial. Dissertação (Mestrado em Saúde Pública) Universidade de São Paulo, São Paulo, 2007.

CONAMA. Conselho Nacional de Meio Ambiente. Resolução n.335 de 2003. Brasília: CONAMA, 2003.

DIAS, R.. Gestão Ambiental. São Paulo: Atlas, 2007.

DIAS, R.. Gestão ambiental: responsabilidade social e sustentabilidade. São Paulo: Atlas, 2006.

EMBRAPA. Empresa Brasileira de Pesquisa Agropecuária. Sistema brasileiro de classificação de solos: 3ㅇa aproximação. Rio de Janeiro, 1988.

FURTADO, J. S.. Sustentabilidade empresarial: guia de práticas econômicas, ambientais e sociais. Salvador: CRA, 2005.

GIL, A. C.. Métodos e técnicas de pesquisa social. São Paulo: Atlas, 1999.
KEINERT, T. M. M.. Organizações sustentáveis: utopias e inovações. São Paulo: Annablume, 2007.

KEMERICH, P. D. C.; BORBA, W. F.. Cemitérios e os problemas ambientais: a dura realidade brasileira. Conselho em Revista, v.10, p.36-37, 2013.

KEMERICH, P. D. C.; UCKER, F. E.; BORBA, W. F.. Cemitérios Como Fonte de Contaminação Ambiental. Scientific American Brasil, v.1, p.78-81, 2012.

MARCONDES, A. W.. A Trilha da Sustentabilidade. São Paulo: EnvolVerde, 2007.

MARTINS, T.. O conceito de desenvolvimento sustentável e seu contexto histórico: algumas considerações. Teresina: Jus Navigandi, 2004.

MEGLIORINI, E.. Custos: análise e gestão. 3 ed. São Paulo: Makron Books, 2012.

MINAYO, C. S.. Pesquisa social: teoria, método e criatividade. 23 ed. Petrópolis: Vozes, 2001.

NEIRA, A.. Metrópoles (in)sustentáveis. Rio de Janeiro: Relume Dumará, 2007.

PACHECO, A.. Os cemitérios e o ambiente. Conselho em Revista, v.24, p.30, 2006.

SACHS, I.. Caminhos para o desenvolvimento sustentável. Rio de Janeiro: Garamond, 2003.

A CBPC - Companhia Brasileira de Produção Científica (CNPJ: 11.221.422/0001-03) detém os direitos materiais desta publicação. Os direitos referem-se à publicação do trabalho em qualquer parte do mundo, incluindo os direitos às renovações, expansões e disseminações da contribuição, bem como outros direitos subsidiários. Todos os trabalhos publicados eletronicamente poderão posteriormente ser publicados em coletâneas impressas sob coordenação da Sustenere Publishing, da Companhia Brasileira de Produção Científica e seus parceiros autorizados. Os (as) autores (as) preservam os direitos autorais, mas não têm permissão para a publicação da contribuição em outro meio, impresso ou digital, em português ou em tradução. 